\title{
İşletmelerde İç Kontrol Sistemi ve Stok Yönetimi: TRA1 Düzey 2 Bölge Uygulaması $\left({ }^{1}\right)$
}

\begin{tabular}{ccc} 
& & Turan ÖNDEŞ $\left(^{\mathbf{2}}\right)$ \\
& & Şule ÇIFTCI $\left(^{3}\right)$ \\
\hline Geliş Tarihi/ Received & Kabul Tarihi/ Accepted & Yayın Tarihi/ Published \\
$28 / 11 / 2017$ & $16 / 12 / 2019$ & $25 / 01 / 2020$ \\
\hline
\end{tabular}

Citation/Atıf: Öndeş, T. ve Çiftci, Ş., (2020), İşletmelerde İç Kontrol Sistemi ve Stok Yönetimi: TRA1 Düzey 2 Bölge Uygulamas1, Atatürk Üniversitesi İktisadi ve İdari Bilimler Dergisi, 34(1):63-80, DOI: 10.16951/atauniiibd.358591

Öz: Bu çalışmanın amacı; Erzurum, Erzincan ve Bayburt illerinde faaliyet gösteren işletmelerin iç kontrol sistemi ve stok yönetimi uygulamalarını değerlendirmek ve iç kontrol sistemi ile stok yönetimi arasında bir ilişkinin olup olmadığını araştırmaktır. Üç bölümden oluşan anket çalışması Erzurum, Erzincan ve Bayburt'ta faaliyet gösteren işletmelerin yöneticilerine uygulanmıştır. Araştırmanın ana kütlesini bu illerde faaliyet gösteren 82 işletme oluşturmaktadır. Bu işletmelerden 68 tanesinden geri dönüş alınmıştır. Araştırma sonucunda, işletme yöneticilerine iç kontrol sistemi ile ilgili sorular sorulduğunda yöneticilerin hem iç kontrol sitemi hem stok yönetimi ile ilgili ifadelere olumlu cevaplar verdiği görülmüştür. İç kontrol sistemi ve stok yönetim puan ortalamalarına bakıldığında "katılıyorum" ifadesine oldukça yakın sonuçlara ulaşılmıştır. Araştırmada, iç kontrol sistemi ile stok yönetimi arasında pozitif güçlü bir ilişki olduğu tespit edilmiştir. Ayrıca, işletmelerdeki iç kontrol sisteminin stok yönetimini anlamlı oranda etkilediği bulunmuştur.

Anahtar Kelimeler: İç Kontrol, Stok Yönetimi, İșletme, TRA1, Düzey 2

Internal Control System and Stock Management in Businesses: TRA1 Level 2 Region Implementation

Abstract: The purpose of this study is to evaluate internal control systems and stock management implementations of businesses in Erzurum, Erzincan and Bayburt (TRA1-Level2) and to research whether there is a relation between internal control system and stock management or not. Three-part survey study was aplied to managers of these businesses. The population in this study consisted of 82 businesses. 68 of 82 businesses agreed to participate to the study. As a result of the study, it was observed that managers responded positively to internal control system and stock management questions. The average of the internal control system and stock management points were quite close in response to "agree". It was determined that there was a positive strong relation between internal control system and stock management. Besides, it was found that internal control system in businesses affected stock management significantly.

Keywords: Internal Control, Stock Management, Business, TRA1, Level 2

${ }^{1}$ Bu makale "İşletmelerde İç Kontrol Sistemi ve Stok Yönetimi: TRA1 Düzey 2 Bölge Uygulaması" isimli yüksek lisans tezinden uyarlanmıştır.

2 Prof. Dr. Atatürk Üniversitesi, İktisadi ve İdari Bilimler Fakültesi, İşletme Bölümü, https://orcid.org/0000-0001-6580-7372

${ }^{3}$ Ar. Gör. Ağrı İbrahim Çeçen Üniversitesi, İktisadi ve İdari Bilimler Fakültesi, İşletme Bölümü, https://orcid.org/0000-0003-1498-6897 


\section{Purpose of the Study}

\section{EXTENDED SUMMARY}

The purpose of this study is to evaluate the internal control system and stock management practices of businesses operating in Erzurum, Erzincan and Bayburt provinces and to investigate whether there is a relationship between internal control system and stock management.

\section{Research Questions}

What is internal control system and stock management?

What are the elements of the internal control system?

Is there a relationship between stock management and internal control system?

\section{Literature Research}

When the national and international literature was searched, it was seen that there were many studies about the internal control system. It was concluded that the studies on the internal control system are generally concentrated in the field of audit, and the studies related to the management were limited. Akyel (2010) investigated the concept of internal control, its elements and effectivenessin his study. He stated that there were some problems in the operation of the internal control system in our country and the internal control system should be reviewed continuously.

Omurbek and Altay (2011) investigated the effectiveness of the internal control system in five-star hotels in the Manavgat region and found that there were some problems in the implementation of the internal control system in the food and beverage departments. They stated that the cost of food and beverage production could be reduced within the framework of certain standards with an effective internal control system. In his study, Akbulut (2012) investigated the existence of the internal control environment in sunflower oil plants in the Thrace Region through a questionnaire and concluded that there is no control environment to increase the efficiency of the internal control system. Turedi (2012) stated that for the persistence of success in buinesses, businesses should continue their activities in accordance with the elements of total quality management and internal control system.

\section{Method}

As of the date of the survey (March 2016), there were 82 active businesses in total, 53 in Erzurum, 26 in Erzincan and 3 in Bayburt. 68 of these businesses gave feedback. The questionnaire was created by asking 6 questions including demographic data initially, 20 questions for internal control afterwards and 15 questions for stock management.

While creating statements for internal control in the questionnaire, we used the scales in master thesis of Selim CENGIZ called 'Examination of Accounting and Internal Control Systems of Exporting Companies and Analysis of Control Risk: Ankara Case' and Emre AKBULUT's 'Measurement of the Efficiency of Internal Control System in Sunflower Oil Sector in Thrace Region. 
İsletmelerde Iç̧ Kontrol Sistemi ve Stok Yönetimi: TRA1 Düzey 2 Bölge Uygulaması

Since there was no scale related to the purpose of inventory management, the statements in the scale were based on the internal control system. Validity and reliability analyzes were performed for the questionnaire. As a result of the analysis, reliability coefficients of internal control system $(\alpha=0.92)$ and stock management $(\alpha=0.94)$ were found to be quite high. The questions were formed according to the 5-point likert scale (strongly disagree, disagree, undecided, agree, strongly agree). The data obtained from the questionnaires were interpreted using SPSS 20.0 (Statistical Package for Social Science for Windows). Frequency, Cronbach Alpha, Anova (One Way Analysis of Variance), Kruskall Wallis, Pearson Correlation and Simple Linear Regression analyzes were applied.

\section{Conclusion and Evaluation}

In this study, it was aimed to evaluate the internal control system and stock management practices of businesses and to investigate the relationship between internal control system and stock management. For this purpose, a survey was conducted to the businesses operating in Erzurum Erzincan and Bayburt provinces which are classified as TRA1 Level 2 in the regional planning of Northeast Anatolia Development Agency. The data obtained from the survey was analyzed with SPSS 20.0. As a result of the study, it was determined that there is no significant relationship between the age and education of the business managers and the internal control system and stock management of the businesses. In addition, it was concluded that there was no significant relationship between the year of operation, legal structure, sector of activity and internal control system and stock management. On the other hand, there was a significant relationship between the internal control system and stock management of the businesses. In other words, it was concluded that companies which care about internal control system also care about inventory management.

\section{I.Giriş}

İşletmeler küreselleşme ile birlikte sürekli biçimde büyümektedir. Dolayısıyla işletmelerin faaliyetleri giderek daha karmaşık bir hal almaktadır. İşletmeler bu faaliyetlerin her aşamasını kontrol etmekte zorlanmaktadır. İç kontrol sistemi faaliyetlerin başından sonuna kadar her aşamasında kullanılan bir süreçtir. İşletmelerin bütün paydaşları bu sürecin içindedir ve dolayısı ile süreçten etkilenir.

Etkili bir iç kontrol sistemi işletmeler için güven unsurudur. İç kontrol sistemi işletmenin amaç ve hedeflerine erişebilmesi için oluşturulan ve işletmenin en alt kademedeki personelden en üst kademeye kadar bütün çalışanlar tarafından etkilenen ve her faaliyet için uygulanan yöntem ve politikaları içine alan bir süreçtir (Doyrangöl, 2002: 33).

Çalışmada, Erzurum, Erzincan ve Bayburt illerinde faaliyet gösteren işletmelerin mevcut iç kontrol sistemi ve stok yönetimi uygulamalarının incelenmesi amacıyla anket çalışması yapılmıştır. Yapılan anket çalışmasından elde edilen veriler SPSS 20.0 (Statistical Package for the Social Sciences) programı ile değerlendirilmiştir. 


\section{II. İç Kontrol Sistemi}

İç kontrol, Avrupa'da ilk kez Londra'da oluşturulan İç Denetim Meslek Birlikleri'nin yayınladığı özel raporda 'organizasyonun planı ile işletmenin varlıklarını korumak, muhasebe bilgilerinin doğruluğunu ve güvenilirliğini araştırmak, faaliyetlerin verimliliğini arttırmak, saptanmış yönetim politikalarına bağl1lığ yöntemleri içerir"' şeklinde tanımlanmıştır (Güredin; 2007: 315- 316).

Hileli Finansal Raporlama Ulusal Komisyonu, ABD'de mali raporlamadaki usulsüzlüklerin artması sebebiyle iç kontrol çerçevesinin yeniden düzenlenmesi için çalışmalar yapmıştır. Komisyon, bu çalışmalar ışığında COSO'yu (The Comittee of Sponsoring Organizations) oluşturmuştur (Gönen; 2009: 192).

\section{A. İ̧ Kontrol Sisteminin Unsurları}

İşletmelerde iç kontrol sisteminin yeterli olup olmadığını, iç kontrol sisteminin unsurları aracıllğıyla belirlemek mümkündür. $\mathrm{Bu}$ konu ile ilgili Uluslararası Denetim Standartlarından "400 Risk Değerlemesi ve İç Kontrol" standardı iç kontrol sisteminin unsurlarını; muhasebe sistemi, kontrol ortamı ve kontrol prosedürleri olmak üzere üç grupta toplamıştır. Ancak bu standarttan sonra COSO konuyu daha kapsamlı incelemiş ve unsurları beş grupta toplamıştır. Bunlar: (Kaval, 2005: 124- 125);
1. Kontrol Çevresi (Ortami)
4. Bilgi ve İletişim
2. Risk Değerlendirme
3. Kontrol Eylemleri
5. Gözlem

\section{Kontrol Ortamı}

Kontrol ortamı etkin bir iç kontrol sisteminin ilk adımıdır. Kontrol ortamında üst yönetimin iş ahlakı ve felsefesi bütün paydaşlara ve çalışanlara geçmektedir. İşletmenin her kademesindeki bireyin görev ve yükümlülüklerini iyi bilmesi gerekmektedir. Etkili bir kontrol ortamı diğer kontrol unsurlarını güçlendirirken, zayıf bir kontrol ortamı ise bütün sistemi zayıflatmaktadır (Moeller, 2013: 56). Ortamı kontrol edilebilir hale getirmek yönetimin görevidir. Kontrol ortamı diğer kontrol unsurlarını etkilemektedir.

\section{Risklerin Değerlendirilmesi}

İşletmeler, gerek işletme içi gerekse işletme dişı önemsemesi gereken birçok riskle karşı karşıyadır. İşletmeler karşılaştıkları riskleri değerlendirirken önce amaçlarını belirlemeli, ardından bu amaçlara ulaşmak için muhtemel riskler analiz edilmelidir. Bu sayede, işletmeler riskleri yönetebilme temelini atmış olurlar. İktisadi ve sosyal hayattaki bütün değişiklikler işletmeler için sürekli risk kaynağ oluştururlar. İşletmeler, bu değişiklikler ile ilgili ortaya çıkabilecek muhtemel riskleri belirlemeli ve bu risklere göre davranışlarını düzenlemelidir. (Yılanc1, 2003: 58). İşletmeler aynı sektörde faaliyet gösteren diğer işletmelerin mevcut durumlarını analiz ederek veya kendi işletmelerinin geçmiş yıllardaki durumlarına bakarak karşılabilecekleri riskleri öngörebilirler. Böylece, risklere karşı temkinli davranırlar.

\section{Kontrol Faaliyetleri}


İsletmelerde Iç̧ Kontrol Sistemi ve Stok Yönetimi: TRA1 Düzey 2 Bölge Uygulaması

Kontrol faaliyetleri düzeltici önlemlerin alınabilmesi için gereklidir. Kontrol faaliyetleri, işletmenin amaçlarına ulaşabilmesi ve riskleri öngörebilmesi için uygulanan politika ve prosedürlerdir. Yetkilerin devredilmesi, işgörme performanslarının incelenmesi ve işletme faaliyetlerinin izlenmesi kontrol faaliyetleri kapsamına girmektedir. Kontrol faaliyetleri diğer iç kontrol unsurları ile bütünleştirilmelidir (Akyel; 2010: 87).

\section{Bilgi ve Illetişim}

Mali raporlama bakımından bilgi-iletișim sistemi, muhasebe sistemini kapsayan; işletmelerin varlık ve kaynaklarının ilgili hesaplara aktarılması için, verileri toplama, kaydetme, işleme (kayıtlama ve sınıflandırma), özetleme ve bu özetleri analiz etme ve raporlamada kullanılan tekniklerden oluşur (Yağc1, 2006: 32). Verileri kaydetme işi zamanında yapılmalıdır. Bilginin doğru zamanda ilgili kişilere ulaşması için veriler doğru ve anlaşıır bir biçimde kayıt altına alınmalıdır.

\section{Gözlem}

Gözlem, işletmede planlanan ve gerçekleşen faaliyetlerin kıyaslanmasıdır. İşletmede iç kontrol sisteminin düzenli biçimde gözlenmesi değişim ve gelişimlere uyumun sağlanıp sağlanmadığını belirleme açısından oldukça önemlidir. Ekonomik ve sosyal yaşamdaki değişimler işletmeyi sürekli etkileyeceğinden gözlem faaliyetlerinin de sürekli yapılması gerekmektedir (Türedi, 2016: 12). Gözlem yapılırken kontrol sisteminin etkinliğini azaltabilecek bütün unsurlar dikkatli bir şekilde incelenmelidir.

\section{B. İ̧̧ Kontrol Sistemini Etkileyen Faktörler}

İç kontrol sisteminin dinamik bir süreç olması sebebiyle tüm kurum ve kuruluşlar için tüm zamanlarda etkin olarak işleyen tek bir iç kontrol sisteminin tasarlanması mümkün değildir. İç kontrol zaman içinde hem çeşitli faktörler hem de kazanılan deneyimlere bağlı olarak sürekli gelişir. İç kontrol sistemini etkileyen söz konusu faktörler şunlardır (Erdoğan, 2009: 31);

- İşletmenin büyüklüğü,

- Kurumsal yönetim,

- Değer yaratma,

- Riskler ve firsatlar,
- Yasal düzenlemeler,

- İșletme kültürü,

- Teknolojideki gelişmeler,

- Hesap verme zorunluluğudur.

\section{Stok Yönetimi}

Modern üretim sistemlerinde stoklar her kademeden yöneticiyi yakından ilgilendiren bir sorun haline gelmiştir. Stok politikalarının yanlış seçilmesi ya da uygulanması sebebiyle pekçok işletmenin kritik duruma düşmesi sık rastlanan bir durumdur. Tarım, demir çelik, tekstil, gübre, çimento, şeker vb. temel endüstrilerde, stok fazlalığ1 ya da azlığı nedeniyle ülke ekonomisi zarar görür. İşletmeci için stoklar, bilanço ve kar-zarar hesaplarında yer alan rakamlarla sadece yöneticileri ilgilendiren bir konu gibi görünür. Ancak etkin bir stok sisteminde işletmedeki her birimin rolü vardır (Kobu, 2003: 343-344). 
İşletmeler için stok bulundurmak üretimin ve satışların kesintisiz bir biçimde sağlanması için önemlidir. Birçok sektörde stok miktarı işletmelerin bilançolarında yer alan önemli bir yatırımı ifade eder, dönen değerlerin ve sabit değerlerin büyük bir kısmını oluşturur. İşletmede, en uygun stok miktarının sağlanması ve stoklar üretime verilirken işletmeye en az vergi yükümlülügü getirecek stok politikasının uygulanması önemlidir. Günümüzde işletmeler bilgisayarlardan ve diğer teknolojik aygıtlardan yararlanarak stoklarını satışlara uyumlu hale getirirler. (Okka, 2011: 108).

\section{Stokların Yönetiminde Etkinlik Sağlanması}

İşletmeler, stok yönetiminde etkinliği sağlamak zorundadırlar. Stok yönetiminde etkinliği sağlayabilmek için şu konularda tedbir alınmalıdır (Okka, 2011: 112);

- Gelecek dönemde yapacağı üretim veya satış miktarını tahmin etmek,

- İşletmelerde etkin stok bilgi akışını sağlamak,

- Emniyet stokunun miktarını iyi tahmin etmek,

- Üretim süresini mümkün olan en kisa seviyede tutmak,

- Optimum sipariş miktarını belirlemek,

- Mamul satışlarının yıl içerisindeki dağılımına uygun bir stok politikası takip etmek,

- Tedarikçi firma sayısını arttırmak,

- Stok tutma maliyetlerini azaltmak,

- Stok tedarikinde mümkün olduğu ölçüde standart mal alınmak suretiyle defonun ve hurdaların ortaya çıkmasını önlemek,

- Stokları sigorta ettirmek,

- Stok fazlasının oluşması halinde bunu satmak veya değiştirmek suretiyle düzeltmek,

- Mümkün olduğu ölçüde sıfır stokla çalışmaktır.

İç kontrol sistemini etkili bir şekilde oluşturmak yönetimin temel görevlerindendir. Etkili bir şekilde oluşturulmuş iç kontrol sistemi ile stoklar ile ilgili verilecek kararların yerinde olması beklenmektedir. Başka bir ifade ile, iç kontrol sisteminin unsurlarından biri olan risklerin öngörülmesi eğer etkin bir biçimde oluşturulmuşsa, muhtemel bir fiyat artışı öngörülecek ve optimum stok miktarı ona göre belirlenecektir.

\section{Metodoloji}

\section{A. Araştırmanın Amacl}

Yapılan araştırmanın temel amacı; Kuzey Doğu Anadolu Kalkınma Ajansı'nın sınıflandırmasında TRA1 Düzey 2 Bölgesi olarak adlandırılan Erzurum, Erzincan, Bayburt illerinde faaliyet gösteren işletmelerin iç kontrol sistemi ve stok 
İsletmelerde Iç̧ Kontrol Sistemi ve Stok Yönetimi: TRA1 Düzey 2 Bölge Uygulaması

yönetimi durumları hakkında bilgi vermek ve bu bilgiler 1şığında yöneticilere önerilerde bulunmaktır.

\section{B. Araştırmanın Kapsamı ve Yöntemi}

Araştırmada Erzurum, Erzincan ve Bayburt illerinde faaliyet gösteren işletmelerin iç kontrol sistemleri ve stok yönetimleri hakkında bilgi almak amaçlandığından anket formu organize sanayi bölgelerinde bulunan işletme yöneticileri ile yapılmıştır.

Araştırmanın yapıldığı tarih (2016 Mart) itibariyle Erzurum ilinde 53, Erzincan ilinde 26, Bayburt ilinde 3 olmak üzere toplamda 82 işletme faaliyet göstermektedir. $\mathrm{Bu}$ işletmelerden 68 tanesinden geri dönüş alınmıştır. Anket formu ilk olarak demografik verileri içeren 6 soru, ardından iç kontrole yönelik 20 soru ve stok yönetimine yönelik 15 soru sorularak oluşturulmuştur. Anket formunda iç kontrole yönelik ifadeler oluşturulurken Selim CENGIZ'in 'İhracatçı Firmaların Muhasebe ve İç Kontrol Sistemlerinin İncelenmesi ve Kontrol Riskinin Analizi: Ankara Örneği" ve Emre AKBULUT'un 'Trakya Bölgesinde Ayçiçek Yağ 1 Sektöründe İç Kontrol Sistemin Etkinliğinin Ölçülmesi'" adlı yüksek lisans tezlerindeki ölçeklerden yararlanılmıştır. Stok yönetimi ile ilgili amaca yönelik herhangi bir ölçeğe rastlanamadığından ölçekteki ifadeler iç kontrol sistemi baz alınarak oluşturulmuştur. Anket formu için geçerlilik ve güvenlirlik analizleri yapılmıştır. Yapılan analiz sonucunda iç kontrol sistemi $(\alpha=0,92)$ ve stok yönetimi $(\alpha=0,94)$ ölçeklerinin güvenirlik katsayıları oldukça yüksek bulunmuştur. Sorular 5'li likert (Kesinlikle katılmıyorum, katılmıyorum, kararsızım, katılıyorum, kesinlikle katıliyorum) tipine göre oluşturulmuştur. Anketlerden elde edilen veriler Statistical Package for Social Science for Windows (SPSS 20,0) kullanılarak yorumlanmıştır. Araştırmada frekans, Cronbach Alpha, Anova (Tek Yönlü Varyans Analizi), Kruskall Wallis, Pearson Korelasyon ve Basit Doğrusal Regresyon analizleri uygulanmıştır.

\section{Araştırmanın Dayandiğ Hipotezler}

$H_{1}$ : İşletme yöneticilerinin yaşları ile işletmelerin iç kontrol sistemleri arasında fark vardır. vardir.

$\mathrm{H}_{2}$ : İşletme yöneticilerinin yaşları ile işletmelerin stok yönetimleri arasında fark

$H_{3}$ : İşletme yöneticilerinin eğitim durumları ile işletmelerin iç kontrol sistemleri arasinda fark vardır.

$H_{4}$ : İşletme yöneticilerinin eğitim durumları ile işletmelerin stok yönetimleri arasinda fark vardir.

$H_{5}$ : İşletmelerin faaliyet yılı ile iç kontrol sistemleri arasında fark vardır.

$H_{6}$ : İşletmelerin faaliyet yılı ile stok yönetimleri arasında fark vardır.

$H_{7}$ : İşletmelerin hukuki yapısı ile iç kontrol sistemleri arasında fark vardır.

$H_{8}$ : İşletmelerin hukuki yapısı ile stok yönetimleri arasında fark vardır.

$H_{9}$ : İşletmelerin çalışan sayıları ile iç kontrol sistemleri arasında fark vardır.

$H_{10}$ : İşletmelerin çalışan sayısları ile stok yönetimleri arasında fark vardır. 
$H_{11}$ : İşletmelerin faaliyet gösterdiği sektörler ile iç kontrol sistemleri arasında fark vardir.

$H_{12}$ : İşletmelerin faaliyet gösterdiği sektörler ile stok yönetimleri arasında fark vardir.

$H_{13}$ : İşletmelerin iç kontrol sistemleri ve stok yönetimleri arasında ilişki vardır. $H_{14}$ : İşletmelerin iç kontrol sistemlerinin stok yönetimlerine etkisi vardır.

D. Araştırmanın Bulguları ve Değerlendirilmesi

Tablo 1: Demografik Bilgiler

\begin{tabular}{|c|c|c|c|}
\hline $\begin{array}{c}\text { Demografik } \\
\text { Özellik }\end{array}$ & Kategoriler & Frekans & Yüzde \\
\hline \multirow{5}{*}{ Yaş } & 25 ve alt1 & 3 & 4,4 \\
\hline & 26- 30 & 11 & 16,2 \\
\hline & $31-35$ & 16 & 23,5 \\
\hline & 36- 40 & 12 & 17,6 \\
\hline & 41 ve üzeri & 26 & 38,2 \\
\hline \multirow{5}{*}{ Eğitim } & İlk-Ortaokul & 5 & 7,4 \\
\hline & Lise & 18 & 26,5 \\
\hline & Önlisans & 11 & 16,2 \\
\hline & Lisans & 32 & 47,1 \\
\hline & Yüksek Lisans & 2 & 2,9 \\
\hline \multirow{5}{*}{ Faaliyet Yılı } & 5 ve alt1 & 15 & 22,1 \\
\hline & 6- 10 & 13 & 19,1 \\
\hline & $11-15$ & 7 & 10,3 \\
\hline & 16- 20 & 9 & 13,2 \\
\hline & 21 ve üzeri & 24 & 35,3 \\
\hline \multirow{5}{*}{ Hukuki Yapı } & A.Ş & 22 & 32,4 \\
\hline & L.T.D & 32 & 47,1 \\
\hline & Şahıs İşletmesi & 11 & 16,2 \\
\hline & Kollektif & 1 & 1,5 \\
\hline & Diğer & 2 & 2,9 \\
\hline \multirow{5}{*}{ Çalışan Sayısı } & 24 ve alt1 & 36 & 52,9 \\
\hline & $25-50$ & 18 & 26,5 \\
\hline & $51-100$ & 7 & 10,3 \\
\hline & $101-150$ & 3 & 4,4 \\
\hline & 151 ve üzeri & 4 & 5,9 \\
\hline \multirow{9}{*}{ Sektör } & Gida & 21 & 30,9 \\
\hline & İnşaat & 18 & 26,5 \\
\hline & İletişim & 2 & 2,9 \\
\hline & Mobilya & 4 & 5,9 \\
\hline & Ambalaj- Plastik- Cam & 4 & 5,9 \\
\hline & Boya- Kimya & 2 & 2,9 \\
\hline & Lojistik & 3 & 4,4 \\
\hline & Matbaa- Reklam & 1 & 1,5 \\
\hline & Diğer & 13 & 19,1 \\
\hline
\end{tabular}


İsletmelerde Iç̧ Kontrol Sistemi ve Stok Yönetimi: TRA1 Düzey 2 Bölge Uygulaması

Çalışmada, 68 işletme ankete katılmıştır. Tablo 1.1 ve 1.2 'de işletme yöneticilerinin \%38'inin 41 ve üzeri yaş aralığında olması, işletmelerin hukuki yapılarının genel olarak Limited ve Anonim Şirket olması, daha çok gıda ve inşaat sektöründe faaliyet göstermesi dikkat çekici bir husustur.

$H_{1}$ : Işsletme yöneticilerinin yaşları ile işletmelerin iç kontrol sistemleri arasinda fark vardir.

Tablo 2. Yöneticilerin Yaşı Bakımından İşletmelerin Iç̧ Kontrol Sisteminin Incelenmesi

\begin{tabular}{|c|c|c|c|c|}
\hline Değişken & Yaş & Ortalama & S.S. & P \\
\hline \multirow{3}{*}{ İç Kontrol Sistemi } & 25 ve altı & 4,28 & 0,29 & \\
\cline { 2 - 4 } & $26-30$ & 3,92 & 0,86 & \\
\cline { 2 - 4 } 0 & $31-35$ & 4,06 & 0,69 & \multirow{2}{*}{0,238} \\
\cline { 2 - 4 } & $36-40$ & 4,21 & 0,51 & \\
\cline { 2 - 4 } & 41 ve üzeri & 3,75 & 0,59 & \\
\hline
\end{tabular}

Tablo 2'de yöneticilerin yaşları bakımından işletmelerin iç kontrol sistemi incelendiği zaman $\mathrm{p}$ değeri $0,238^{\prime}$ dir. Bu değer 0,05 'den büyük olduğuna göre işletme yöneticilerinin yaşı bakımından iç kontrol sisteminde anlamlı bir farklılık olduğu söylenemez. Dolayısı ile $H_{l}$ reddedilmiştir. fark vardır.

$\mathrm{H}_{2}$ : İsletme yöneticilerinin yaşları ile işletmelerin stok yönetimleri arasında Tablo 3. Yöneticilerin Yaşı Bakımından Işşletmelerin Stok Yönetiminin İncelenmesi

\begin{tabular}{|c|c|c|c|c|}
\hline \multirow{2}{*}{ Değişken } & Yaş & Ort. & S.S. & \multirow{2}{*}{ P } \\
\hline \multirow{3}{*}{ Stok Yönetimi } & 25 ve alt1 & 3,67 & 0,70 & \\
\cline { 2 - 4 } & $26-30$ & 3,64 & 1,10 & \multirow{2}{*}{0,910} \\
\cline { 2 - 4 } & $31-35$ & 3,93 & 0,64 & \\
\cline { 2 - 4 } & $36-40$ & 3,87 & 0,70 & \\
\cline { 2 - 4 } & 41 ve üzeri & 3,79 & 0,84 & \\
\hline
\end{tabular}

Tablo 3'de yöneticilerin yaşları bakımından işletmelerin stok yönetimi incelendiği zaman $\mathrm{p}$ değeri 0,910 'dur. $\mathrm{Bu}$ değer 0,05 'den büyük olduğuna göre işletme yöneticilerinin yaşı bakımından stok yönetiminde anlamlı bir farklılık olduğu söylenemez. Dolayısı ile $H_{2}$ reddedilmiştir.

$H_{3}$ : Işsletme yöneticilerinin eğitim durumlart ile işletmelerin iç kontrol sistemleri arasında fark vardır. 
Tablo 4. Yöneticilerin Eğitim Durumları Bakımından İşletmenin Iç̧ Kontrol Sisteminin Incelenmesi

\begin{tabular}{|c|c|c|c|c|}
\hline Değişken & Eğitim & Ortalama & S.S. & P \\
\hline \multirow{4}{*}{$\begin{array}{c}\text { İç Kontrol } \\
\text { Sistemi }\end{array}$} & İlk-ortaokul & 3,46 & 0,78 & \\
\cline { 2 - 4 } & Lise & 3,87 & 0,73 & \\
\cline { 2 - 4 } & Önlisans & 3,93 & 0,74 & \multirow{2}{*}{0,217} \\
\cline { 2 - 4 } & Lisans & 4,05 & 0,54 & \\
\cline { 2 - 4 } & Yüksek Lisans & 4,60 & 0,28 & \\
\hline
\end{tabular}

Tablo 4'de yöneticilerin eğitim durumları bakımından işletmelerin iç kontrol sistemi incelendiği zaman $\mathrm{p}$ değeri 0,217 çıkmıştır. Bu değer 0,05 'den büyük olduğuna göre işletme yöneticilerinin eğitim durumları bakımından iç kontrol sisteminde anlamlı bir farkl11ık olduğu söylenemez. Dolayısı ile $H_{3}$ reddedilmiştir.

$H_{4}$ : Issletme yöneticilerinin eğitim durumlart ile işletmelerin stok yönetimleri arasinda fark vardır.

Tablo 5. Yöneticilerin Eğitim Durumları Bakımından Işsletmenin Stok Yönetiminin Incelenmesi

\begin{tabular}{|c|c|c|c|c|}
\hline Değişken & Ĕgitim & Ortalama & S.S. & P \\
\hline \multirow{4}{*}{ Stok Yönetimi } & Illk-ortaokul & 3,01 & 1,33 & \\
\cline { 2 - 4 } & Lise & 3,76 & 0,77 & \multirow{2}{*}{0,101} \\
\cline { 2 - 4 } & Önlisans & 3,71 & 1,00 & \\
\cline { 2 - 4 } & Lisans & 3,94 & 0,59 & \\
\cline { 2 - 4 } & Yüksek Lisans & 4,53 & 0,47 & \\
\hline
\end{tabular}

Tablo 5'de yöneticilerin eğitim durumları bakımından işletmenin stok yönetimi incelendiği zaman $\mathrm{p}$ değeri 0,217 çıkmıştır. Bu değer 0,05 'den büyük olduğuna göre işletme yöneticilerinin eğitim durumları bakımından stok yönetiminde anlamlı bir farklılık olduğu söylenemez. Dolayısı ile $H_{4}$ reddedilmiştir.

$H_{5}$ : Işsletmelerin faaliyet yılı ile iç kontrol sistemleri arasında fark vardır.

Tablo 6. İşletmelerin Faaliyet Yılı Bakımından İç Kontrol Sisteminin İncelenmesi

\begin{tabular}{|c|c|c|c|c|}
\hline Değişken & Faal. Yılı & Ortalama & S.S. & P \\
\hline \multirow{4}{*}{ İç Kontrol } & 5 ve alt1 & 3,81 & 0,81 & \\
\cline { 2 - 4 } & $6-10$ & 3,99 & 0,71 & \multirow{3}{*}{0,301} \\
\cline { 2 - 4 } & $11-15$ & 3,55 & 0,72 & \\
\cline { 2 - 4 } & $16-20$ & 4,09 & 0,47 & \\
\cline { 2 - 4 } & 21 ve üzeri & 4,09 & 0,52 & \\
\hline
\end{tabular}

Tablo 6' da işletmelerin faaliyet yılı bakımından iç kontrol sistemi incelendiği zaman $p$ değeri 0,301 çıkmıştır. Bu değer 0,05 'den büyük olduğuna göre işletmelerin faaliyet yılı bakımından iç kontrol sisteminde anlamlı bir farklılık olduğu söylenemez. Bu sebeple $H_{5}$ reddedilmiştir.

$H_{6}:$ Işletmelerin faaliyet yılı ile stok yönetimleri arasında fark vardır. 
İsletmelerde Iç Kontrol Sistemi ve Stok Yönetimi: TRA1 Düzey 2 Bölge Uygulaması

Tablo 7. İşletmelerin Faaliyet Yılı Bakımından Stok Yönetiminin İncelenmesi

\begin{tabular}{|c|c|c|c|c|}
\hline Değişken & Faal. Yılı & Ortalama & S.S. & \multirow{2}{*}{ P } \\
\hline \multirow{4}{*}{ Stok Yönetimi } & 5 ve altı & 3,63 & 0,73 & \\
\cline { 2 - 4 } & $6-10$ & 3,85 & 0,84 & \multirow{3}{*}{0,466} \\
\cline { 2 - 4 } & $11-15$ & 3,42 & 1,02 & \\
\cline { 2 - 4 } & $16-20$ & 3,89 & 0,85 & \\
\cline { 2 - 4 } & 21 ve üzeri & 3,98 & 0,75 & \\
\hline
\end{tabular}

Tablo 7'de işletmelerin işletmelerin faaliyet y1lı bakımından stok yönetimi incelendiği zaman $\mathrm{p}$ değeri 0,466 çıkmıştır. Bu değer 0,05 'den büyük olduğundan dolayı işletmelerin faaliyet yılı bakımından stok yönetiminde anlamlı bir farklılık olduğu söylenemez. Bu yüzden $H_{6}$ reddedilmiştir.

$H_{7}$ : Işsletmelerin hukuki yapısı ile iç kontrol sistemleri arasında fark vardır.

Tablo 8. İşletmelerin Hukuki Yapısı Bakımından İç Kontrol Sisteminin İncelenmesi

\begin{tabular}{|c|c|c|c|c|}
\hline Değişken & Huk. Yapı & Ortalama & S.S. & \multirow{2}{*}{ P } \\
\hline \multirow{4}{*}{ İç Kontrol Sistemi } & A.Ş. & 3,96 & 0,60 & \multirow{3}{*}{$0,131^{*}$} \\
\cline { 2 - 4 } & L.T.D. & 4,11 & 0,53 & \\
\cline { 2 - 4 } & Şahis İşletmesi & 3,38 & 0,86 & \\
\cline { 2 - 4 } & Kollektif & 4,20 & - & \\
\cline { 2 - 4 } & Diğer & 4,38 & 0,11 & \\
\hline
\end{tabular}

*Varyanslar arasında homojenlik olmadığından Kruskal Wallis ile analiz edilmiştir.

Tablo 8'de işletmelerin hukuki yapısı bakımından iç kontrol sistemi incelendiği zaman $p$ değeri 0,131 çıkmıştır. Bu değer 0,05 'den büyük olduğuna göre işletmelerin hukuki yapısı bakımından iç kontrol sisteminde anlamlı bir farklılık olduğu söylenemez. Dolayısı ile $\mathrm{H}_{7}$ hipotezi reddedilmiştir.

$H_{8}$ : İsletmelerin hukuki yapısı ile stok yönetimleri arasında fark vardır.

Tablo 9. İsletmelerin Hukuki Yapısı Bakımından Stok Yönetiminin İncelenmesi

\begin{tabular}{|c|c|c|c|c|}
\hline Değişken & Huk. Yapı & Ortalama & S.S. & P \\
\hline \multirow{4}{*}{ Stok Yönetimi } & A.Ş. & 3,83 & 0,71 & \multirow{2}{*}{$0,074 *$} \\
\cline { 2 - 4 } & L.T.D. & 4,01 & 0,61 & \multirow{2}{*}{0,12} \\
\cline { 2 - 4 } & Şahis İşletmesi & 3,03 & - & \\
\cline { 2 - 4 } & Kollektif & 4,20 & 0,28 & \\
\cline { 2 - 4 } & Diğer & 4,27 & \\
\hline
\end{tabular}

*Varyanslar arasında homojenlik olmadığından Kruskal Wallis ile analiz edilmiştir.

Tablo 9'da işletmelerin hukuki yapısı bakımından stok yönetimi incelendiği zaman $p$ değeri 0,074 çıkmıştır. Bu değer 0,05 'den büyük olduğuna göre işletmelerin hukuki yapısı bakımından stok yönetiminde anlamlı bir farklılık olduğu söylenemez. Dolayısı ile $\mathrm{H}_{8}$ reddedilmiştir.

$H_{9}$ : İsletmelerin çalışan sayıları ile iç kontrol sistemleri arasında fark vardır. 
Tablo 10. İşletmelerin Çalışan Sayıları Bakımından İç Kontrol Sisteminin Incelenmesi

\begin{tabular}{|c|c|c|c|c|}
\hline Değişken & Çalışan Sayısı & Ortalama & S.S. & P \\
\hline \multirow{4}{*}{$\begin{array}{c}\text { İç Kontrol } \\
\text { Sistemi }\end{array}$} & 24 ve altı & 3,84 & 0,69 & \multirow{2}{*}{0,606} \\
\cline { 2 - 4 } & $25-50$ & 4,13 & 0,66 & \\
\cline { 2 - 4 } & $51-100$ & 4,04 & 0,36 & \\
\cline { 2 - 4 } & $101-150$ & 3,95 & 0,83 & \\
\cline { 2 - 4 } & 151 ve üzeri & 4,08 & 0,63 & \\
\hline
\end{tabular}

Tablo 10'da İşletmelerin çalışan sayıları bakımından iç kontrol sistemi incelendiği zaman $\mathrm{P}$ değeri 0,606 bulunmuştur. $\mathrm{Bu}$ değer 0,05 'den büyük olduğuna göre işletmelerin çalışan sayıları bakımından iç kontrol sisteminde anlamlı bir farklı1ık olduğu söylenemez. Dolayısı ile $\mathrm{H}_{9}$ reddedilmiştir.

$H_{10}$ : Işsletmelerin çalışan sayısları ile stok yönetimleri arasında fark vardır.

Tablo 11. İşletmelerin Çalışan Sayıları Bakımından Stok Yönetiminin İncelenmesi

\begin{tabular}{|c|c|c|c|c|}
\hline Değişken & Çalışan Sayısı & Ortalama & S.S. & P \\
\hline \multirow{4}{*}{ Stok Yönetimi } & 24 ve altı & 3,63 & 0,92 & \multirow{2}{*}{0,347} \\
\cline { 2 - 4 } & $25-50$ & 4,03 & 0,63 & \\
\cline { 2 - 4 } & $51-100$ & 3,87 & 0,50 & 0,71 \\
\cline { 2 - 4 } & $101-150$ & 3,87 & 0,64 & \\
\cline { 2 - 4 } & 151 ve üzeri & 4,25 & \\
\hline
\end{tabular}

Tablo 11'de işletmelerin çalışan sayıları bakımından stok yönetimi incelendiği zaman $p$ değeri 0,347 çıkmıştır. Bu değer 0,05 'den büyük olduğuna göre işletmelerin çalışan sayıları bakımından stok yönetiminde anlamlı bir farklılık olduğu söylenemez. Dolayısı ile $\mathrm{H}_{10}$ reddedilmiştir. fark vardir.

$H_{11}$ : Işsletmelerin faaliyet gösterdiği sektörler ile iç kontrol sistemleri arasında

Tablo 12. İşletmelerin Sektörleri Bakımından Iç̧ Kontrol Sisteminin İncelenmesi

\begin{tabular}{|c|c|c|c|c|}
\hline Değișken & Sektör & Ortalama & S.S. & $\mathbf{P}$ \\
\hline \multirow{9}{*}{$\begin{array}{c}\text { İç Kontrol } \\
\text { Sistemi }\end{array}$} & G1da & 3,96 & 0,67 & \multirow{9}{*}{0,083} \\
\hline & İnşaat & 4,12 & 0,50 & \\
\hline & İletişim & 4,60 & 0,57 & \\
\hline & Mobilya & 4,35 & 0,42 & \\
\hline & $\begin{array}{c}\text { Ambalaj- } \\
\text { Plastik-Cam }\end{array}$ & 3,96 & 0,28 & \\
\hline & Boya-Kimya & 4,05 & 1,06 & \\
\hline & Lojistik & 4,15 & 0,64 & \\
\hline & $\begin{array}{l}\text { Matbaa- } \\
\text { Reklam }\end{array}$ & 2,80 & - & \\
\hline & Diğer & 3,53 & 0,75 & \\
\hline
\end{tabular}


İşletmelerde Iç̧ Kontrol Sistemi ve Stok Yönetimi: TRA1 Düzey 2 Bölge Uygulaması

Tablo 12'de işletmelerin sektörleri bakımından iç kontrol sistemi incelendiği zaman $p$ değeri 0,083 çıkmıştır. Bu değer 0,05 'den büyük olduğuna göre işletmelerin sektörü bakımından iç kontrol sisteminde anlamlı bir farklılık olduğu söylenemez. Dolayısı ile $\mathrm{H}_{11}$ reddedilmiştir. vardir.

$\mathrm{H}_{12}$ : Iş̧letmelerin faaliyet gösterdiği sektörler ile stok yönetimleri arasında fark

Tablo 13. Işsletmelerin Sektörleri Bakımından Stok Yönetiminin İncelenmesi

\begin{tabular}{|c|c|c|c|c|}
\hline Değişken & Sektör & Ortalama & S.S. & $\mathbf{P}$ \\
\hline \multirow{9}{*}{ Stok Yönetimi } & G1da & 3,87 & 0,88 & \multirow{9}{*}{0,249} \\
\hline & İnşaat & 3,78 & 0,73 & \\
\hline & İletişim & 4,60 & 0,57 & \\
\hline & Mobilya & 4,37 & 0,60 & \\
\hline & $\begin{array}{c}\text { Ambalaj-Plastik- } \\
\text { Cam }\end{array}$ & 3,97 & 0,16 & \\
\hline & Boya-Kimya & 3,80 & 0,57 & \\
\hline & Lojistik & 3,53 & 1,42 & \\
\hline & Matbaa-Reklam & 2,07 & - & \\
\hline & Diğer & 3,59 & 0,72 & \\
\hline
\end{tabular}

Tablo 13'de işletmelerin sektörleri bakımından stok yönetimi incelendiği zaman $p$ değeri 0,249 çıkmıştır. Bu değer 0,05 'den büyük olduğuna göre işletmelerin sektörü bakımından stok yönetiminde anlamlı bir farklılık olduğu söylenemez. Dolayısı ile $\mathrm{H}_{12}$ hipotezi reddedilmiştir. vardir.

$H_{13}$ : Işletmelerin iç kontrol sistemleri ve stok yönetimleri arasında ilişki

Tablo 14: Isşletmelerin İ̧̧ Kontrol Sistemleri ve Stok Yönetimleri Arasındaki Illişki

\begin{tabular}{|c|c|c|c|}
\cline { 3 - 4 } \multicolumn{2}{c|}{} & İç Kontrol Sistemi & Stok Yönetimi \\
\hline \multirow{3}{*}{ İç Kontrol Sistemi } & $\mathrm{R}$ & 1 & 0,817 \\
\cline { 2 - 4 } & $\mathrm{P}$ & - & 0,000 \\
\cline { 2 - 4 } & $\mathrm{N}$ & 68 & 68 \\
\hline \multirow{3}{*}{ Stok Yönetimi } & $\mathrm{R}$ & 0,817 & 1 \\
& $\mathrm{P}$ & 0,000 & - \\
\cline { 2 - 4 } & $\mathrm{N}$ & 68 & 68 \\
\hline
\end{tabular}

Tablo 14'de işletmelerin iç kontrol sistemleri ve stok yönetimleri arasında ilişki olup olmadığının incelenebilmesi için korelasyon analizi yapılmıştır. p değeri 0,000 çıkmıştır bu değer 0,05 'den küçük olduğu için işletmelerin iç kontrol sistemi ve stok yönetimi arasında anlamlı bir ilişki olduğu görülmektedir. Araştırmada $\mathrm{R}$ değeri 0,817 çıkmıştır. Bu değer 1'e yakın olduğu için bu ilişkinin güçlü ve pozitif olduğu söylenebilir. Dolayısı ile $H_{13}$ kabul edilmiştir.

$H_{14}$ : Işsletmelerin iç kontrol sistemlerinin stok yönetimlerine etkisi vardır. 
Tablo 15: İşletmelerin İç Kontrol Sisteminin Stok Yönetimine Etkisinin İncelenmesi

\begin{tabular}{|c|c|c|c|c|}
\hline \multicolumn{5}{|c|}{ Model Özeti } \\
\hline Model & $\mathrm{R}$ & $\mathrm{R} 2$ & Düzeltilmiş R2 & $\begin{array}{c}\text { Tahmini } \\
\text { Standart Hata }\end{array}$ \\
\hline 1 & 0,817 & 0,667 & 0,662 & 0,46621 \\
\hline
\end{tabular}

Tablo 15'de işletmelerin iç kontrol sisteminin stok yönetimine etkisinin olup olmadığının incelenebilmesi için regresyon analizi yapılmıştır. R2 değeri 0,667 olarak bulunmuştur. Bu sonuca göre, işletmelerin stok yönetimlerindeki değişimin \%66,2 kısmı iç kontrol sistemlerindeki değişim tarafından açıklanmaktadır. Dolayısı ile $\mathrm{H}_{14}$ hipotezi kabul edilmiştir.

Tablo 16. Varyans Analizi Tablosu

\begin{tabular}{|c|c|c|c|c|c|c|}
\hline \multicolumn{2}{|c|}{ Model } & $\begin{array}{c}\text { Kareler } \\
\text { Toplamı }\end{array}$ & df & $\begin{array}{c}\text { Ortalama } \\
\text { Kare }\end{array}$ & F & P \\
\hline \multirow{3}{*}{1} & Regresyon & 28,723 & 1 & 28,723 & 132,150 & 0,000 \\
\cline { 2 - 7 } & Kalınt1 & 14,345 & 66 & 0,217 & \multicolumn{2}{|c}{} \\
\cline { 2 - 6 } & Toplam & 43,068 & 67 & \multicolumn{3}{|c}{} \\
\hline
\end{tabular}

Tablo 16'da F değeri anlamlı olduğu için modelin tümüyle anlamlı olduğu söylenebilir. İşletmelerin stok yönetimlerinin iç kontrol sistemleriyle açıklandığ1 model anlamlı bir modeldir.

Tablo 17. Parametre Tahmini

\begin{tabular}{|c|c|c|c|c|c|c|}
\hline \multirow{2}{*}{\multicolumn{2}{|c|}{ Model }} & \multicolumn{2}{|c|}{$\begin{array}{c}\text { Standardize } \\
\text { Edilmemiş Katsayı }\end{array}$} & \multirow{2}{*}{$\begin{array}{c}\text { Standardize } \\
\text { Edilmiş Katsayı } \\
\text { Beta }\end{array}$} & \multirow{2}{*}{$\mathbf{T}$} & \multirow{2}{*}{$\mathbf{P}$} \\
\hline & & Beta & $\begin{array}{l}\text { Standart } \\
\text { Hata }\end{array}$ & & & \\
\hline \multirow{2}{*}{1} & (Sabit) & $-0,149$ & 0,349 & \multirow{2}{*}{0,817} & $-0,429$ & 0,670 \\
\hline & İKS & 1,000 & 0,087 & & 11,496 & 0,000 \\
\hline
\end{tabular}

Tablo 17'de işletmelerdeki iç kontrol sisteminin stok yönetimine ne kadar etki ettiğini gösteren tablo bulunmaktadır. Tabloya göre, işletmelerde iç kontrol sistemi bir birim artarsa stok yönetimininde bir birim artacağı görülmektedir.

\section{Sonuc}

Küresel rekabet ortamında işletmeler avantaj sağlayabilmek için etkin bir biçimde oluşturulmuş iç kontrol sistemine ihtiyaç duyarlar. Çünkü etkin bir iç kontrol sistemi ile muhasebe işlemlerinin doğru miktarlarda, uygun hesaplara zamanında kaydedilmesi, varlıkların korunması, hata ve usulsüzlüklerin önlenmesi ve ortaya çıkarılması amaçlanmaktadır. İç kontrol sistemi işletme içerisinde doğru ve güvenilir bilgi akışının olmasına imkân verir.

İşletmeler üretim programlarının aksamadan gerçekleşmesini arzu ederler. $\mathrm{Bu}$ amaç doğrultusunda işletmeler stok bulundurmayı düşünürler. Öte yandan işletmeler minimum düzeyde sermaye kullanarak faaliyetlerini sürdürmek isterler. Stok 
İsletmelerde Iç̧ Kontrol Sistemi ve Stok Yönetimi: TRA1 Düzey 2 Bölge Uygulaması

bulundurmak da depolama gibi bazı maliyetlere katlanmayı gerektirir. Bu yüzden stok miktarının belirlenmesi işletmeler için oldukça önemlidir. İyi oluşturulmuş bir stok yönetimi stok maliyetlerini göz önünde bulundurarak optimum stok seviyesinin belirlenip üretim programlarının aksamamasını sağlar. Etkili bir biçimde oluşturulmuş iç kontrol sistemi ile stok yönetiminde etkinlik sağlamak mümkündür. Çalışma ile iç kontrol sistemi ve stok yönetimi arasındaki ilişkinin ortaya çıkarılması amaçlanmıştır.

Çalışma, Kuzeydoğu Anadolu Kalkınma Ajansı'nın yaptığı bölge planlamasında TRA1 Düzey 2 sinıflandırmasında yer alan Erzurum Erzincan ve Bayburt illerinde faaliyet gösteren işletmelere yapılmıştır. Çalışma sonucunda, işletme yöneticilerinin yaşı ve eğitimi ile işletmelerin iç kontrol sistemi ve stok yönetimi arasında anlamlı bir ilişki olmadığı saptanmıştır. Ayrıca işletmelerin faaliyet yılı, hukuki yapısı, faaliyette bulunduğu sektör ile iç kontrol sistemi ve stok yönetimi arasında anlamlı bir ilişki olmadığı sonucuna ulaşılmıştır. Buna karşılık işletmelerin iç kontrol sistemi ve stok yönetimleri arasında anlamlı bir ilişki olduğu belirlenmiştir. Diğer bir deyişle; iç kontrol sistemine önem veren işletmelerin stok yönetimine de önem verdiğini söylemek mümkündür.

\section{Kaynaklar}

Akbulut, E. (2010). Trakya Bölgesinde Ayçiçek Yağı Sektöründe İç Kontrol Sisteminin Etkinliğinin Ölçülmesi, Yüksek Lisans Tezi, Trakya Üniversitesi Sosyal Bilimler Enstitüsü.

Akyel, R. (2010). "Türkiye'de İç Kontrol Kavramı, Unsurları ve Etkinliğinin Değerlendirilmesi', Yönetim ve Ekonomi Dergisi, 17(1) s. 84-98.

Ataman, Ü., Hacırüstemoğlu, R., \& Bozkurt, N. (2001). Muhasebe Denetimi Uygulamaları, İstanbul: Alfa Basım, 1.

Candan, E. (2006). Kamu İdarelerinde İç Kontrol Sistem ve Süreçlerinin Tasarlanmas1, Uygulanması Ve Geliştirilmesinde Uyulacak Usul ve Esaslar. Mali Yönetim ve Denetim Dergisi, 38, 18-33.

Cengiz, S. (2010). İhracatçı Firmaların Muhasebe ve İç Kontrol Sistemlerinin İncelenmesi ve Kontrol Riskinin Analizi: Ankara örneği (Master's thesis, Hitit Üniversitesi Sosyal Bilimler Enstitüsü).

Çatak, S. (2005). İşletmelerde İç Kontrol Sistemini Oluşturan Unsurlardan Kontrol Çevresinin (Ortamı) İncelenmesi. Mevzuat Dergisi, 1-9.

Demirbaş, M., \& Uyar, S. (2006). Kurumsal Yönetim İlkeleri ve Denetim Komitesi. Güncel Akademi.

Doyrangöl, N.C. (2002) 'İşletme Çevresindeki Olumsuz Gelişmeler Karşısında İç Denetimin Yeri ve Önemi'”. Mali Çözüm Dergisi. s.33-40

Erdoğan, S. (2009). İç Kontrol Sistemi: Kamu İktisadi Teşebbüsleri İçin İç Kontrol Modeli Önerisi. Devlet Planlama Teşkilatı Uzmanlık Tezi.

Gönen, S. (2009). "İç Kontrol Sisteminin Unsurlarından Kontrol Ortamının İncelenmesine Yönelik Bir Araştırma”, Muhasebe Bilim Dünyası Dergisi, 11(1). S.189-217. 
Güredin, E. (2007). Denetim ve Güvence Hizmetleri, (11.Bask1). İstanbul: Arıkan Yayinları.

Kaval, H. (2005). Muhasebe Denetimi. (1.Bask1). Ankara: Gazi Kitabevi.

Kobu, B. (2003). Üretim Yönetimi. (11.Bask1). İstanbul: Avcıol Baım Yayın.

Moeller, R.R. (2013). Executive's Guide to COSO Internal Controls: Understanding and Implementing The New Framework, John Wiley \& Sons

Münevver, Y. (2001). Muhasebe Bilgi Sistemi, İç Kontrol ve Verimlilik Üçgeni. Muhasebe Bilim Dünyası Dergisi, 3(3), 37-50.

Okka, O. (2011). İşletme Finansmanı, Ankara: Nobel Yayın Dağıtım.

Ömürbek, V., \& Altay, S. Ö. (2011). Turizm İşletmelerinde İç Kontrol Sisteminin Etkinliğinin İncelenmesi ve Manavgat Bölgesindeki Beş Yıldızlı Otellerde Bir Araştırma. Süleyman Demirel Üniversitesi İktisadi ve İdari Bilimler Fakültesi Dergisi, 16(1), 379-402.

Tümer, S. (2010). Kamuda İç Kontrol Sistemi ve Uygulama Aşamaları. Güncel Mevzuatı Araştırma Ve Eğitim Derneği Yayınları, Ankara.

Türedi H., Koban A. O. (2016). 'COSO İç Kontrol Modelinde Risk Değerlendirme Faaliyetleri' Journal of Marmara University Social Sciences Institute/Öneri Dergisi 12(46)

Türedi, S. (2012). İç Kontrol Sistemi Ve Toplam Kalite Yönetimi İlişkisi. Uluslararası Alanya İşletme Fakültesi Dergisi, 4(1), 27-37.

Usul, H., Titiz, İ., \& Ateş, B. A. (2011). İç Kontrol Sisteminin Kurumsal Yönetimin Olusumundaki Etkinliği: Marmara Bölgesi Belediye İsletmelerine Yönelik Bir Uygulama. Muhasebe ve Finansman Dergisi, (49), 48-54.

Uyar, S. (2009). İç Kontrol Ve İç Denetim: 5018 sayılı kanun açısından değerlendirme. Gazi Kitabevi, Ankara.

Yağcı, S. (2006). İşletmelerde İç Kontrol Sisteminin İncelenmesi. (Yüksek Lisans Tezi) İstanbul: Marmara Üniversitesi Sosyal Bilimler Enstitüsü

Yılancı, M. (2003). İç Denetim: Türkiye'nin 500 Büyük Sanayi İşletmesi Üzerine Bir Araştırma, Osmangazi Üniversitesi Yayınları No: 086, Eskişehir. 